\title{
Characterization of the Dairy Farm Environment in Great Britain and the Effect of the Farm Environment on Cow Life Span
}

\author{
M. J. Haskell, ${ }^{* 1}$ S. Brotherstone, ${ }^{*} \dagger$ A. B. Lawrence, ${ }^{*}$ and I. M. S. White† \\ *Sustainable Livestock Systems Group, Scottish Agricultural College, Edinburgh, EH9 3JG, United Kingdom \\ †Institute of Evolutionary Biology, University of Edinburgh, West Mains Road, Edinburgh, EH9 3JT, United Kingdom
}

\begin{abstract}
Dairy farms vary a great deal in the feeding and management systems that are used. These differences affect the performance of the cows, and some genotypes may be affected more than others. If effects of such genotype-by-environment interactions $(\mathrm{G} \times \mathrm{E})$ are large, then farmers must be made aware of them to make informed breeding decisions. To investigate $\mathrm{G} \times \mathrm{E}$, a classification system for farm environments was developed based on national- and fine-level data from dairy herds across the United Kingdom. The national data included herd and yield characteristics and local weather information. The fine-level data included information on feeding and management systems on farms, and was obtained from survey results from 778 farms. A principal components analysis of the surveys identified 2 major dimensions characterizing the data. The first dimension explained $14.6 \%$ of the variation and was related to the level of production intensity. The second dimension explained $11.5 \%$ of the variation and was related to climate. Information on milk yield, herd characteristics, and climate was then extracted from national databases for the survey farms. A canonical correlation analysis was used to relate the survey data to the variables extracted from the national data set to determine the most relevant variables. The canonical correlation between the chosen sets of national data and survey variables was 0.62 . This environmental classification was then used to determine how the farm environment affects the life span of dairy cows. The life span of the daughters of 1,000 sires was related to the type of farm environment. The daughters of a majority of sires showed a "plastic" response, with increased life span in less intensive farms. The daughters of a smaller number of sires showed a more generalized response, with life span being less affected by the environment. This $\mathrm{G} \times \mathrm{E}$ suggested that sires vary in the sensitivity
\end{abstract}

Received December 20, 2006.

Accepted June 28, 2007.

${ }^{1}$ Corresponding author: marie.haskell@sac.ac.uk of their daughters to different farm environments. This variation in response could allow breeding companies and farmers to match sires to particular farm environments.

Key words: genotype $\times$ environment interaction, life span, herd environment

\section{INTRODUCTION}

Dairy farms vary a great deal in feeding and management systems. In some instances, cows are housed throughout the year and fed high levels of concentrate feed, whereas in others, the cows are grazed throughout the year. The particular conditions that the cow or herd experiences can be called the farm environment (FE). The particular type of $\mathrm{FE}$ affects the production and health of the cows, and there may be differences between genotypes in the way they respond to the different types of FE. When a given environmental difference has more effect on some genotypes than on others, a genotype-by-environment interaction $(\mathbf{G} \times \mathbf{E})$ is present (Falconer, 1989). A number of studies have shown a scaling effect where environment affects performance in all genotypes (i.e., performance of all genotypes is better in a good environment), but there is no re-ranking of genotypes (Cromie et al., 1998; Kolmodin et al., 2002; Boettcher et al., 2003; Kearney et al., 2004; Mulder et al., 2004). Other studies have shown reranking of genotypes, in which breeds or sires rank differently in different $\mathrm{FE}$, often where the genotypes or feeding systems differed substantially (CienfuegosRivas et al., 1999; Kolver et al., 2002; Hayes et al., 2003). The variation in performance with environment is also known as environmental sensitivity.

Investigating the extent of $\mathrm{G} \times \mathrm{E}$, particularly those for which reranking occurs, is important for a number of reasons. Quantifying the degree of environmental sensitivity shown by individual sires provides information on the performance of their daughters in different $\mathrm{FE}$ and allows us to identify sires as specialists (those ranking highly in certain $\mathrm{FE}$ ) or generalists (those ranking similarly across FE). For the individual farmer, breeding decisions could be improved if information 
were available on the suitability of sires for particular FE. Identifying genotypes that are unsuitable for specific FE is important in terms of health and welfare. Additionally, international bull evaluations currently treat each country as a single entity in terms of $\mathrm{FE}$ (Schaeffer, 1994; Banos and Sigurdsson, 1996), despite large countries having great variation in the production systems used and small neighboring countries having similar FE (Weigel and Rekaya, 2000; Zwald et al., 2003). If FE or management system could be used in bull evaluations rather than geographical boundaries, it would improve the accuracy of calculating international breeding values.

To assess the extent of environmental sensitivity, environmental factors must be quantified (possibly on a continuous scale), and then the relationship between $\mathrm{FE}$ and the trait or traits of interest can be explored. A number of methods for quantifying the FE exist. In some studies, a single aspect of the FE has been used (Cromie et al., 1998; Ravagnolo and Misztal, 2000; Mulder et al., 2004), whereas others have incorporated multiple environmental factors, such as cows per herd, milk production, and rainfall, into a single environmental score (e.g., Weigel and Rekaya, 2000; Zwald et al., 2003; Bryant et al., 2005; Windig et al., 2005).

Random regression models have often been used to investigate environmental sensitivity in production and fertility traits (e.g., Kolmodin et al., 2002; Calus and Veerkamp, 2003; Hayes et al., 2003; Bryant et al., 2006; Windig et al., 2006). However, the effect of FE on the health of dairy cattle is also important to investigate, because it may indicate that some $\mathrm{FE}$ are unsuitable for particular genotypes. Using the bulk tank SCS as a measure of FE, Calus et al. (2006) found significant $\mathrm{G} \times \mathrm{E}$ when SCS during early lactation were assessed. Health- and welfare-related traits, such as longevity, often appear to show lower genetic correlations across countries in international evaluations than do production traits, suggesting that these traits may be more sensitive to differences in FE (Mark, 2004).

The aims of this study were 1) to derive a useful categorization of herds in the United Kingdom by obtaining detailed information from farmers on their management and feeding systems, 2) to relate this finescale, farm-level data to information available at the national level to provide a definition of $\mathrm{FE}$, and 3) to assess the effect of FE on life span.

\section{MATERIALS AND METHODS}

\section{Farmer Questionnaire}

The farmer questionnaire contained 20 questions on the farm, cattle housing, feeding, and management. The first 3 questions asked about the nearest town, the postal code (to allow the nearest weather station and the soil class to be identified), and the herd number (to allow milk recorder data to be extracted). The fourth asked about the dominant breed, to allow non-Holstein and Holstein-Friesian herds to be excluded. The questions had a number of different formats. For some, a numeric answer was required (e.g., amount of concentrate fed per cow per year, age of heifers at first mating). For others, a tick-box approach was used and ordered categories were given (e.g., number of milking cows on the farm, month of turnout). The third type of question required a yes or no or qualification type of answer [e.g., organic or nonorganic, separation of first-lactation heifers from older cows (yes, no, for a short period after calving)]. The questionnaire was distributed to farmers by the field officers of the 2 major milk recording organizations (MRO) in Great Britain.

A total of 1,273 questionnaires from across Great Britain were returned. Of the surveys returned, 6.7\% were from farms with a majority of cows that were not Holstein, Holstein-Friesian, or British Friesian. These farms were excluded from further analyses. A question on the number of acres the farm covered was included, but the range of answers returned indicated that the question was not framed correctly to obtain the information required or that the question had been misunderstood. Tables 1 and 2 show the means, ranges, and scales for the responses to the questionnaire. A number of relevant variables, such as length of the housing period (month cows in to month cows out to pasture), and the length of the calving period (1 season vs. 2 seasons vs. all year round) were calculated from the answers. To calculate values when the farmer's answer was categorical, such as the ratio of cows to staff members, the midpoint of the category was used. Because a number of farmers had not entered answers to some of the questions, the analyses were based on $778 \mathrm{com}$ plete questionnaires.

\section{Weather and Soil Class Data}

Based on the postal code of the farm, the dominant land use class for England and Wales was obtained from the National Soil Resources Institute (Cranfield University, Silsoe, UK) and the land capability for agriculture class was obtained for Scotland (Macaulay Institute, Aberdeen, Scotland) for the $2 \mathrm{~km}^{2}$ that most closely matched the postal code for each farm. Because the 2 systems are slightly different, a common system was devised, and each farm was assigned a land class score, which then ranged from class 1 , for land capable of producing a very wide range of crops, to class 7 , for land of very limited agricultural value. Most farms had land classes between class 2 and class 4 . The postal 
Table 1. Summary of responses to questions in the farmer questionnaire that required a numeric response

\begin{tabular}{lccc}
\hline Item & Minimum & Mean & Maximum \\
\hline Months housed, n & 3 & 7 & 12 \\
Cows/staff member, n & 8 & 70 & 325 \\
Age of maiden heifers at first mating, mo & 12 & 18 & 36 \\
Average amount of concentrates fed, t/cow per yr & 0 & 2.0 & 4.8 \\
Space allowance of free stalls, stalls/100 cows & 50 & 106 & 217 \\
Space allowance of straw yards, m $^{2}$ & 1.8 & 6.5 & 15 \\
\hline
\end{tabular}

Table 2. Summary of responses to the questions from the farmer questionnaire with categorical answers ${ }^{1}$

\begin{tabular}{|c|c|}
\hline Question & Response \\
\hline \multicolumn{2}{|l|}{ Is the farm organic? } \\
\hline No & 94.2 \\
\hline \multirow{2}{*}{\multicolumn{2}{|c|}{$\begin{array}{l}\text { Yes } \\
\text { Does the vet visit routinely? }\end{array}$}} \\
\hline & \\
\hline No & 52.9 \\
\hline Yes & 47.1 \\
\hline \multicolumn{2}{|l|}{ Are cows fed in the parlor? } \\
\hline No & 16.9 \\
\hline Yes & 83.1 \\
\hline \multicolumn{2}{|l|}{ Is concentrate fed in a TMR? } \\
\hline No & 51.9 \\
\hline Yes & 48.1 \\
\hline \multicolumn{2}{|l|}{ Calving duration } \\
\hline One season & 20.4 \\
\hline Two seasons & 2.2 \\
\hline Year round & 77.4 \\
\hline \multicolumn{2}{|l|}{ Are the heifers housed separately? } \\
\hline No & 88.2 \\
\hline Postcalving & 8.1 \\
\hline Yes & 3.7 \\
\hline \multicolumn{2}{|l|}{ Number of milkings per day? } \\
\hline One & 0.4 \\
\hline Two & 98.5 \\
\hline Three & 0.9 \\
\hline Robotic milking & 0.2 \\
\hline \multicolumn{2}{|l|}{ Housing system } \\
\hline Free stalls & 71.8 \\
\hline Straw yards and free stalls & 12.7 \\
\hline Straw yards & 14.8 \\
\hline Other & 0.7 \\
\hline \multicolumn{2}{|l|}{ Periods grazing } \\
\hline Cows housed throughout year & 0.8 \\
\hline Housed in winter and spring calvers housed in summer & 2.0 \\
\hline Housed in winter and at night in summer & 11.2 \\
\hline Housed only in winter & 85.8 \\
\hline Outdoors throughout year & 0.2 \\
\hline \multicolumn{2}{|l|}{ Size of group cows are housed in } \\
\hline$<25$ & 0.8 \\
\hline $25-49$ & 15.3 \\
\hline $50-79$ & 30.2 \\
\hline $80-99$ & 21.5 \\
\hline $100-149$ & 21.4 \\
\hline$>150$ & 10.8 \\
\hline \multicolumn{2}{|l|}{ Total number of cows } \\
\hline$<50$ & 5.3 \\
\hline $50-99$ & 29.3 \\
\hline $100-149$ & 33.6 \\
\hline $150-199$ & 18.2 \\
\hline $200-249$ & 7.1 \\
\hline $250-299$ & 3.5 \\
\hline$>300$ & 3.0 \\
\hline
\end{tabular}

${ }^{1}$ The scores assigned to the categories within a question follow the ascending order of the categories as shown in the table. code was also used to locate the nearest weather station that gave information on rainfall, air temperature, soil temperature, and sunshine. The total monthly rainfall $(\mathrm{mm})$, mean monthly hours of bright sunshine per day, mean monthly air temperature $\left({ }^{\circ} \mathrm{C}\right)$, and mean monthly soil temperature $\left({ }^{\circ} \mathrm{C}\right)$ for the years 1999 to 2003 , inclusive, were obtained from the Met Office (Exeter, UK), and overall means were calculated for the 5 -yr period and for the summers (April to September) and winters (October to March).

\section{Analysis of the Farmer Questionnaire}

A principal components analysis (PCA) with a correlation matrix was used to analyze the data (Jobson, 1992). The results of these analyses are often represented in graphs showing the position (or loading) of each of the input variables with respect to the principal components, which are drawn as the axes. For our study, the response to each question was entered as a separate input variable into the PCA, as were the land class of the farm and the weather variables for the nearest weather station. An initial analysis of the weather variables showed that the air temperature, soil temperature, and hours of sunshine were closely associated, and the mean summer, mean winter, and yearly mean figures for each variable were very similar. Therefore, only the mean temperature and mean rainfall were used in subsequent analyses. No other clusters of data were found. Examination of the eigenvalues indicated that 2 of the components explained more of the variation in the data than did the others, so interpretation of the results focused on these 2 components.

\section{Data from the National MRO}

Traits chosen to describe the FE at the national level were herd averages for milk, fat, and protein yields; average age at first calving; and average herd size. In addition, we used farm postal codes recorded on the MRO databases to locate the meteorological station nearest the farm and so obtain the relevant average annual temperature and average annual rainfall.

Lactation 1 to lactation 5 305-d production records of calvings between 1998 and 2004 were extracted from 
the national database. This time period was chosen to reflect the current dairy cattle breeding population. After deleting first-lactation records when the age at calving was less than 17 mo or greater than 40 mo and deleting herds with fewer than 5 first-lactation cows, $1,221,475$ production records from 3,886 herds remained.

For each herd, the average age at first calving and herd size were calculated. Herd solutions for milk, fat, and protein yields were obtained by using the following fixed effects model:

$$
y_{i j k l}=\mu+l a c_{j}+\beta_{j} \text { age }+y m_{k}+h e r d_{l}+e_{i j k l},
$$

where $y$ is the milk, fat, or protein yield of the $i$ th cow, $\mu$ is the overall mean, lac is the effect of the $j$ th lactation $(\mathrm{j}=1,2, \ldots 5), \beta_{j}$ is the regression coefficient associated with age at calving within lactation $j, y m_{k}$ is the effect of the $k$ th year-month of calving, herd $d_{l}$ is the effect of the $l$ th herd, and $e$ is the random residual error. Age at calving was expressed as a within-lactation deviation from the mean ages of $30 \mathrm{mo}$ (lactation 1), 44 mo (lactation 2), 58 mo (lactation 3), 72 mo (lactation 4), and 86 mo (lactation 5), and herd solutions were adjusted to lactation 2 equivalents.

\section{Canonical Correlation Analysis of Questionnaire and National Data}

Our aim was to assess the relationship between variables from the questionnaire data and variables from national data. A canonical correlation analysis is a generalization of multiple regression that allows one to investigate the relationship between 2 sets of variables. Given a set of G-variables and a set of F-variables, one can calculate the correlation between any given linear combination of the G-variables with a given linear combination of the F-variables. The maximum value of this correlation (because the coefficients of the linear combinations are allowed to vary) is the first canonical correlation, and the corresponding linear combinations of $\mathrm{G}$ and $\mathrm{F}$ are the first canonical variables. The second canonical correlation and variables are defined as the set of variables, uncorrelated with the first set, that have the maximum correlation, and so on.

The G-variables in this analysis were available for all farms and comprised herd solutions for milk, fat, and protein yields; age at first calving; herd size; temperature; and rainfall. The F-variables, specific to the farms in the survey, were chosen because they had high loadings on the first dimension of the PCA analysis, and were further refined by consultation with farm experts to reflect the different farming systems. The variables were months outside, number of cows, regular veterinary visits ( $0=$ no, $1=$ yes $)$, and amount of concentrates fed ( $t$ /cow per yr).

Farms in the survey were matched to the national data by using herd numbers. Many herd numbers were incorrectly specified on the survey forms, and national data were obtained on only 419 of the possible 778 survey farms. The canonical correlation analysis was therefore based on G- and F-variables from these 419 herds.

\section{Life Span Analysis}

The life span of a cow can be considered an overall indicator of the health of the animal in a specific $\mathrm{FE}$ and, to some extent, is a measure of how well the animal is matched to her FE. Life span data (Brotherstone et al., 1997) were extracted for daughters of approximately 11,000 sires in 3,879 national herds calving between 1998 and 2004. Because this created an extremely sparse sire $\times$ herd $(\mathbf{S} \times \mathbf{H})$ incidence table, the data were reduced to records of daughters of the 1,000 most widespread sires. After this reduction, the number of herds per sire varied from 26 to more than 1,000 , and the total number of daughters with data was $\sim 400,000$. To avoid the consequences of length-biased sampling, the life span of each cow was measured from the year she entered the data window of 1998 to 2004 . For example, a cow calving for the first time in 1996 and dying in 2000 was credited with lactations only during or after 1998.

We fitted 2 models to the data. Model [1] fitted sire, herd, and $\mathrm{S} \times \mathrm{H}$ as random effects:

$$
\mathrm{Y}_{\mathrm{ijk}}=\mu+\operatorname{sire}_{\mathrm{i}}+\operatorname{herd}_{\mathrm{j}}+(\mathrm{S} \times \mathrm{H})_{\mathrm{ij}}+\mathrm{e}_{\mathrm{ijk}},
$$

where $Y_{\mathrm{ijk}}$ is the life span score for the kth daughter of sire $\mathrm{i}$ in herd $\mathrm{j}$. Model [2] was obtained from model [1] by adding $\bar{s} \mathrm{G}_{\mathrm{j}}$ and $\left(s_{i}-\bar{s}\right) \mathrm{G}_{\mathrm{j}}$, where $\mathrm{G}_{\mathrm{j}}$ is the $\mathrm{FE}$ score for herd $j$, and $s_{i}$ is the sensitivity for the ith sire. The herd and $\mathrm{S} \times \mathrm{H}$ terms remain, and in model [2] represent residual effects (herd or $\mathrm{S} \times \mathrm{H}$ effects unexplained by overall regression on $G_{j}$ or variation in the slope of that regression). Retaining these terms is important in preserving the correct variance-covariance structure in the mixed model. Omitting them would create an inhomogeneous residual variance and possibly biased tests of other fixed and random effects in the model.

Model [2] is a random regression model (Schaeffer and Dekkers, 1994) with a random intercept and slope for each sire. The covariance between intercept and slope was included in the model. 


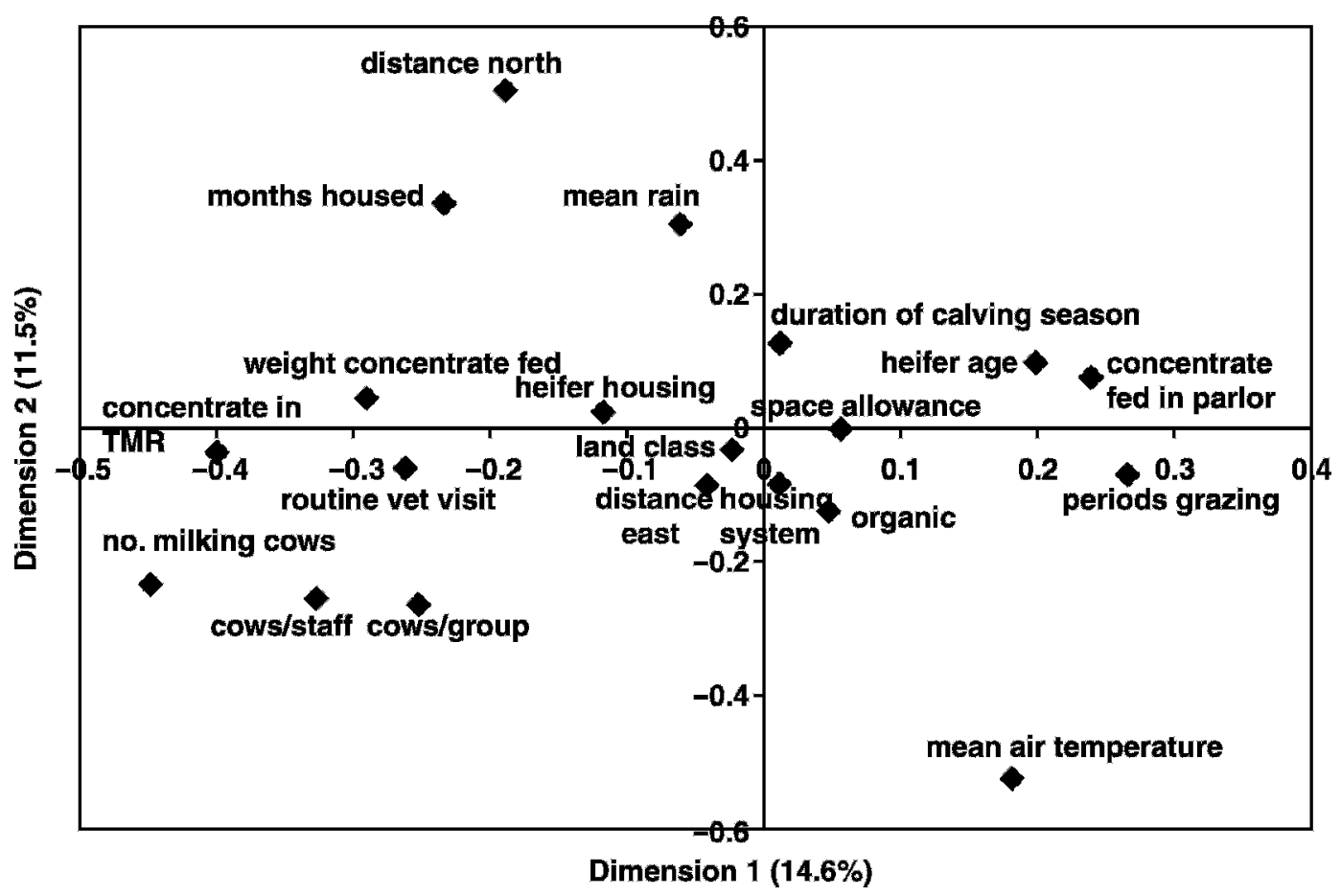

Figure 1. Results of the principal components analysis from the farmer questionnaire. The 2 principal components with the largest eigenvalues are shown as the $\mathrm{x}$ - and $\mathrm{y}$-axes, respectively. The loading for each of the input variables with respect to these 2 dimensions is shown. The loading represents the relationship between the maximum values for each input variable (e.g., large number of milking cows, high number of months housed). For categorical responses, "yes" was considered greater than "no."

\section{RESULTS}

\section{Farmer Survey}

When all informative variables were included in the analysis, the first 2 principal components explained 14.6 and $11.5 \%$ of the variation, respectively (Figure 1). Dimension 1 is presented on the $\mathrm{x}$-axis and appears to be related to the level of input, because it contrasts farms that graze the cows for large periods of the year and feed concentrate in the milking parlor (because these input variables have strong positive loadings on dimension 1) with farms with a large number of cows and that feed high levels of concentrate in a mixed ration (these inputs have strong negative loadings on dimension 1). Dimension 2 (on the y-axis) appears to be related to climate, because increasing latitude (north), number of months per year housed, and rainfall had high positive loadings, and high air temperature had a large negative loading.

\section{Canonical Correlation Analysis}

The first canonical variables, scaled in each case so that the maximum coefficient was \pm 1 , were:

$$
\begin{gathered}
\mathrm{F}=\text { concentrates }+0.553 \times \text { veterinary visits } \\
+0.332 \times \text { no. of cows }-0.005 \times \text { months out }, \text { and } \\
G=- \text { temperature }-0.296 \times \text { age }+0.175 \times \text { protein } \\
-0.092 \times \text { rain }-0.090 \times \text { fat }+0.005 \times \text { milk. }
\end{gathered}
$$

The corresponding canonical correlation between $\mathrm{F}$ and $\mathrm{G}$ was 0.62 . The first canonical F-variate could be interpreted as a measure of system input, with large values corresponding to high-input farms (high concentrate usage, frequent veterinary visits, a large number of cows that spend a lower than average time out at grass). The corresponding G-variate could be used for the same purpose with the larger sample of farms selected from the MRO databases.

\section{Life Span Analysis}

Table 3 shows the estimated variance components for the model omitting environmental sensitivity (model [1]) and for the model including environmental sensitivity (model [2]). The sire variance was the same for both models. The reduction in the herd term for model [2] represents the contribution of the overall re- 
Table 3. Estimated variance components for a model excluding the environmental sensitivity term (model [1]) and a model including this term (model [2]) $)^{1}$

\begin{tabular}{lccccc}
\hline & \multicolumn{2}{c}{ Variance component } & & \\
\cline { 2 - 3 } Term & Model $[1] \pm \mathrm{SE}$ & Model [2] & Difference & Change, \% \\
\hline Sire & $0.084 \pm 0.005$ & 0.084 & 0.000 & 0.0 \\
Herd & $0.188 \pm 0.006$ & 0.174 & 0.014 & 7.4 \\
$\mathrm{~S} \times \mathrm{H}^{2}$ & $0.109 \pm 0.004$ & 0.104 & 0.005 & 4.6 \\
\hline
\end{tabular}

${ }^{1} \mathrm{SE}$ were similar for both models.

${ }^{2}$ Sire-by-herd interaction.

gression to the herd variance. Similarly, the reduction in the $\mathrm{S} \times \mathrm{H}$ term represents the contribution of the variation in the slope of the regression to the $\mathrm{S} \times \mathrm{H}$ variance. This explained about $4.5 \%$ of the $\mathrm{S} \times \mathrm{H}$ interaction.

Fitting model [2] produces 2 BLUP (Henderson, 1948) for each sire: the intercept, representing the average sire effect on longevity over all $\mathrm{FE}$, and the slope, representing sensitivity, or the extent to which the sire effect is dependent on the FE score. Variance components for the intercept and slope were both statistically significant. Figure 2 shows a histogram of the sensitivity BLUPs from model [2] for the 1,000 sires represented in the data set. For nearly all sires, the sensitivity coefficient was negative, indicating that, in general, life span tended to be greater in low-input FE. However, the effect varied from sire to sire. Daughters of sires with sensitivity coefficients around zero tended to be long-lived in any FE (i.e., generalists), whereas daughters of sires with negative coefficients tended to live longer in low-input rather than high-input FE (i.e., specialists).

\section{DISCUSSION}

The first principal component from the farmer survey data contrasted farms with large numbers of cows that

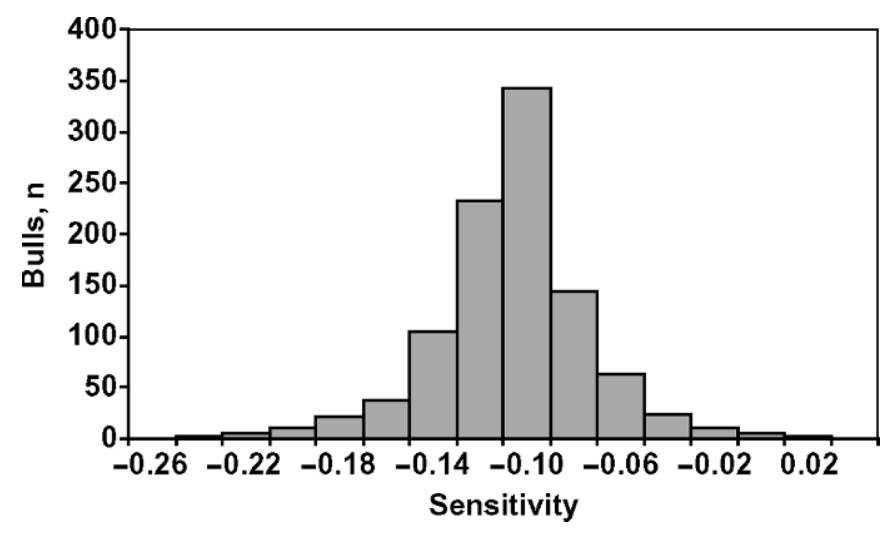

Figure 2. Histogram of the sensitivity (or slope) BLUPs. fed large amounts of concentrate in a TMR with farms that fed concentrate in the milking parlor, housed the cows for shorter periods, and mated the maiden heifers at an older age. This result could be interpreted as quantifying production intensity. Using similar methods, Windig et al. (2005) found that variables relating to the level of milk production had high loadings on their first principal component, and also concluded that production intensity was a defining characteristic of their sample farms. Other authors have concluded that herd size is also important in defining the FE (Fikse et al., 2003; Zwald et al., 2003). The second principal component from the farmer survey data in this study related to climate, with high air temperature contrasting with increasing latitude (north of the equator) and rainfall. Associations among climate and herd characteristics, production, and fertility have also been shown in a number of other studies (Weigel and Rekaya, 2000; Fikse et al., 2003; Hayes et al., 2003; Zwald et al., 2003; Oseni et al., 2004; Bryant et al., 2005). However, the total percentage of variation explained by the PCA was relatively low, but was similar to that shown by Windig et al. (2006). This may indicate that farming systems are inherently diverse or that, in the future, analyses should be used that identify the most informative variables and discard the others. In this study, the farm characteristics that seemed to have a close relationship with the production intensity dimension, such as the number of cows in the herd and the amount of concentrate feed used, were taken forward for use in the canonical correlation analysis.

The survey farms provided data that could be used to measure system input directly. The purpose of the canonical correlation analysis was to find a way to measure system input on national farms. Because data on key variables, such as months outside and veterinary visits, were not available, this had to be indirect. The signs of the coefficients of the first canonical F-variable (from survey data) were such that the F-variable could be interpreted as a direct measure of system input. High concentrate use, frequent veterinary visits, large herd size, and a short time out on grass all contributed to a large F-variable, and vice versa. There was no simple interpretation for the corresponding first canonical G-variable (from national data). Nevertheless, the substantial correlation of 0.62 between the 2 variables suggests $\mathrm{G}$ as a potentially useful indirect measure of system input.

In the life span analysis, the variance components from model [1] imply a heritability for life span of 0.08 \pm 0.005 . This across-herd heritability is consistent with the value used in the national genetic evaluations (Brotherstone et al., 1997) and is similar to other estimates (Harris et al., 1992; Short and Lawlor, 1992). 
The genetic correlation between life span in 2 randomly chosen herds was estimated from model [1] as the ratio of the sire variance component to the sum of the sire plus $\mathrm{S} \times \mathrm{H}$ components (see equation [22.12b] on page 671 of Lynch and Walsh, 1998). The correlation of 0.44 \pm 0.018 was clearly significantly less than 1.0 . With model [2], the genetic correlation between life span in 2 herds depended on the FE score (x, y) in those herds. A contour plot over the region $-3<(\mathrm{x}, \mathrm{y})<+3$ (corresponding roughly to the range of $G$ in the data) showed that the correlation is fairly constant at approximately 0.4 to 0.5 when $\mathrm{x}=\mathrm{y}$, but that it falls away to approximately 0.1 to 0.2 as $\mathrm{x}-\mathrm{y} \rightarrow \pm 3$ (and $\mathrm{x}+\mathrm{y}=0$ ). In other words, model [2] predicts relatively low genetic correlations between 2 herds when each is at opposite extremes on the scale of G, whereas model [1] predicts the same correlation whatever the values of $G$.

The regression on $\mathrm{G}$ explained a small but statistically significant proportion of the $\mathrm{S} \times \mathrm{H}$ variance. Despite the small proportion of variance explained, we were able to identify sires showing evidence of contrasting sensitivities. Both specialist and generalist sires were observed. Kolmodin et al. (2002) also found significant variation between sires in their sensitivity to the $\mathrm{FE}$; they observed that sires with high genetic merit for production were more sensitive to changes in the production $\mathrm{FE}$ than sires that had lower genetic merit for production. The presence of environmental sensitivity presents an opportunity for farmers to choose sires based on their own farm type. This may improve dairy cow welfare, because farmers would be able to choose animals that perform well, in terms of health and production, on their own type of farm. Variation among sires has also been shown in production traits (Hayes et al., 2003) and in fertility (Oseni et al., 2004).

The results also suggest that the daughters of some sires live longer in low-input FE than in high-intensity production $\mathrm{FE}$, suggesting that these sires are producing daughters suited to low-input FE. Other studies have shown that health and production varies with $\mathrm{FE}$, but low-intensity FE are not always favored. There is also variation in performance within a herd. For instance, Windig et al. (2005) found that herds with a high level of production had lower average SCC than herds with a low level of production. However, the highest producing cows within these herds had greater SCC. Calus et al. (2005) also showed that herds with high average protein production had lower levels of mastitis, lower SCC, and higher BCS than herds with low average protein, but high-producing animals in these herds had slightly poorer fertility.

If certain FE have adverse affects on health, this raises an animal welfare issue. It would appear that the daughters of certain sires can cope with poorer FE, and this would assist the breeding decisions of farmers. However, further assessment of these animals is necessary to ensure that the apparent coping has no other, as yet unquantified, health or welfare costs. When considering production traits, many authors have concluded that $\mathrm{G} \times \mathrm{E}$ effects need not be considered in the implementation of a breeding program (Boettcher et al., 2003; Calus and Veerkamp, 2003; Kearney et al., 2004). However, the results from the present study and from one assessing SCC (Calus et al., 2006) suggest that environmental information might be taken into account when considering health traits.

Throughout the paper, we have left open the question of how to select sires. There are several possibilities. One could ignore the sensitivity and select in the usual way on the average performance over all $\mathrm{FE}$. As a theoretical possibility, one could also ignore the average performance and select based purely on sensitivity, although it is hard to envisage circumstances under which this would be sensible. Most likely, one would take both aspects of performance into account. One way to do this would be to plot the sensitivity BLUP (y) against average performance BLUP $(x)$ for each candidate bull, and select from a desired subset (e.g., top right). This has long been a common practice among plant breeders (Finlay and Wilkinson, 1963). If selecting for a particular type of $\mathrm{FE}$ (with score $\mathrm{G}$ ), one would select on the basis of $x+G \times y$.

\section{CONCLUSIONS}

The intensity of production and the climate appear to be the most important factors in classifying the FE in terms of cow production and health. Our analysis showed that fine-level data on management and housing from farms can be represented by data available from national databases. A significant $\mathrm{G} \times \mathrm{E}$ for life span was shown. For nearly all sires, the environmental sensitivity coefficient was negative, indicating that, in general, life span was greater in low-intensity systems. However, environmental sensitivity varied from sire to sire, suggesting that sires differ in the sensitivity of their daughters to changes in $\mathrm{FE}$.

\section{ACKNOWLEDGMENTS}

We are very grateful to the staff at National Milk Records (Chippenham, UK) and Cattle Information Service (Rickmansworth, UK) in the United Kingdom for collecting the farmer survey information. The Met Office (Exeter, UK) provided the climate data, and the National Soil Resources Institute, Cranfield University (Silsoe, UK), and the Macauley Institute (Aberdeen, Scotland) provided the soils data. Thanks to Lindsey 
Maggs, Laura Nicoll, and Matt Bell for input of the data. This project was funded by Defra (London, UK), Avoncroft Sires (Bromsgrove, UK), BOCMPauls (Bristol, UK), The Cattle Information Service, Cogent (Chester, UK), Dartington Cattle Breeding Trust (Totnes, UK), Genus (Nantwich, UK), Holstein UK (Rickmansworth, UK), National Milk Records, RSPCA (Horsham, UK), and Scottish Executive Environment and Rural Affairs Department (SEERAD, Edinburgh, UK) through the LINK Sustainable Livestock Production Programme.

\section{REFERENCES}

Banos, G., and A. Sigurdsson. 1996. Application of contemporary methods for the use of international data in national genetic evaluations. J. Dairy Sci. 79:1117-1125.

Boettcher, P. J., J. Fatehi, and M. M. Schutz. 2003. Genotype $\times$ environment interactions in conventional versus pasture-based dairies in Canada. J. Dairy Sci. 86:383-389.

Brotherstone, S., R. F. Veerkamp, and W. G. Hill. 1997. Genetic parameters for a simple predictor of the lifespan of HolsteinFriesian dairy cattle and its relationship to production. Anim. Sci. 65:31-37.

Bryant, J. R., N. López-Villalobos, J. E. Pryce, and C. W. Holmes. 2005. Environmental clustering of New Zealand dairy herds. Page 223 in Proc. Satellite Workshop XXth Int. Grassl. Congr., Cork, Ireland. J. J. Murphy, ed. Wageningen Academic Publishers, Wageningen, the Netherlands.

Bryant, J. R., N. López-Villalobos, J. E. Pryce, C. W. Holmes, and D. L. Johnson. 2006. Reaction norms used to quantify the responses of New Zealand dairy cattle of mixed breeds to nutritional environment. N. Z. J. Agric. Res. 49:371-381.

Calus, M. P. L., L. L. G. Janss, and R. F. Veerkamp. 2006. Genotype by environment interaction for somatic cell score across bulk milk somatic cell count and days in milk. J. Dairy Sci. 89:4846-4857.

Calus, M. P. L., and R. F. Veerkamp. 2003. Estimation of environmental sensitivity of genetic merit for milk production traits using a random regression model. J. Dairy Sci. 86:3756-3764.

Calus, M. P. L., J. J. Windig, and R. F. Veerkamp. 2005. Associations among descriptors of herd management and phenotypic and genetic levels of health and fertility. J. Dairy Sci. 88:2178-2189.

Cienfuegos-Rivas, E. G., P. A. Oltenacu, R. W. Blake, S. J. Schwager, H. Castillo-Juarez, and F. J. Ruiz. 1999. Interaction between milk yield of Holstein cows in Mexico and the United States. J. Dairy Sci. 82:2218-2223.

Cromie, A. R., D. L. Kelleher, F. J. Gordon, and M. Rath. 1998. Genotype by environment interaction for milk production traits in Holstein Friesian dairy cattle in Ireland. Pages 100-104 in Proc. 1998 Interbull Mtg., Rotorua, New Zealand. Interbull, Uppsala, Sweden.

Falconer, D. S. 1989. Introduction to Quantitative Genetics. 3rd ed. Longman, Harlow, UK.

Fikse, W. F., R. Rekaya, and K. A. Weigel. 2003. Assessment of environmental descriptors for studying genotype by environment interaction. Livest. Prod. Sci. 82:223-231.
Finlay, K. W., and G. N. Wilkinson. 1963. The analysis of adaptation in a plant-breeding programme. Aust. J. Agric. Res. 14:742-754.

Harris, B. L., A. E. Freeman, and E. Metzger. 1992. Analysis of herd life in Guernsey dairy cattle. J. Dairy Sci. 75:2008-2016.

Hayes, B. J., M. Carrick, P. Bowman, and M. E. Goddard. 2003. Genotype $\times$ environment interaction for milk production of daughters of Australian dairy sires from test-day records. J. Dairy Sci. 86:3736-3744.

Henderson, C. R. 1948. Estimation of general, specific, and maternal combining abilities in crosses among inbred lines of swine. $\mathrm{PhD}$ Thesis. Iowa State University, Ames.

Jobson, J. D. 1992. Applied multivariate data analysis. Pages 345482 in Categorical and Multivariate Methods. Vol. 2. Springer Verlag, New York, NY.

Kearney, J. F., M. M. Schutz, P. J. Boettcher, and K. A. Weigel. 2004. Genotype $\times$ environment interaction for grazing versus confinement. I. Production traits. J. Dairy Sci. 87:501-509.

Kolmodin, R., E. Strandberg, P. Madsen, J. Jensen, and H. Jorjani. 2002. Genotype by environment interaction in Nordic dairy cattle studied using reaction norms. Acta Agric. Scand. A, Anim. Sci. 52:11-24.

Kolver, E. S., J. R. Roche, M. J. de Veth, P. L. Thorne, and A. R. Napper. 2002. Total mixed rations versus pasture diets: Evidence for a genotype $\times$ diet interaction in dairy cow performance. Proc. N. Z. Soc. Anim. Prod. 62:246-251.

Lynch, M., and B. Walsh. 1998. Genetics and Analysis of Quantitative Traits. Sinauer Assoc. Inc., Sunderland, MA.

Mark, T. 2004. Applied genetic evaluations for production and functional traits in dairy cattle. J. Dairy Sci. 87:2641-2652.

Mulder, H. A., A. F. Groen, G. de Jong, and P. Bijma. 2004. Genotype $\times$ environment interaction for yield and somatic cell score with automatic and conventional milking systems. J. Dairy Sci. 87:1487-1495.

Oseni, S., I. Misztal, S. Tsuruta, and R. Rekaya. 2004. Genetic components of days open under heat stress. J. Dairy Sci. 87:3022-3028.

Ravagnolo, O., and I. Misztal. 2000. Genetic component of heat stress in dairy cattle, parameter estimation. J. Dairy Sci. 83:2126-2130.

Schaeffer, L. R. 1994. Multiple-country comparison of dairy sires. J. Dairy Sci. 77:2671-2678.

Schaeffer, L. R., and J. C. M. Dekkers. 1994. Random regressions in animal models for test day production in dairy cattle. Proc. Fifth World Congr. Genet. Appl. Livest. Prod. 18:443-446.

Short, T. H., and T. J. Lawlor. 1992. Genetic parameters of conformation traits, milk yield, and herd life in Holsteins. J. Dairy Sci. 75:1987-1998.

Weigel, K. A., and R. Rekaya. 2000. A multiple-trait herd cluster model for international dairy sire evaluation. J. Dairy Sci. 83:815-821.

Windig, J. J., M. P. L. Calus, B. Beerda, and R. F. Veerkamp. 2006. Genetic correlations between milk production and health and fertility depending on herd environment. J. Dairy Sci. 89:1765-1775.

Windig, J. J., M. P. L. Calus, and R. F. Veerkamp. 2005. Influence of herd environment on health and fertility and their relationship with milk production. J. Dairy Sci. 88:335-347.

Zwald, N. R., K. A. Weigel, W. F. Fikse, and R. Rekaya. 2003. Identification of factors that cause genotype by environment interaction between herds of Holstein cattle in seventeen countries. J. Dairy Sci. 86:1009-1018. 